\title{
Viaje a Italia a través de las Cantigas Historiadas de Alfonso X el Sabio
}

\author{
Laura MOLINA LÓPEZ \\ Universidad Complutense de Madrid, \\ Departamento de Historia del Arte I (Medieval)
}

\begin{abstract}
RESUMEN
En el año 1256, unas embajadas procedentes de la ciudad de Pisa llegan a Soria para proponer a Alfonso $\mathrm{X}$ la candidatura para ocupar el trono imperial, apelando a la existencia de lazos de sangre que unían al Rey Sabio con la dinastía de los Staufen. La propuesta realizada por los pisanos, puso en marcha una política imperial que tuvo su repercusión en la producción artística de Alfonso X. En el caso de las Cantigas de Santa María hallamos relatos de milagros acontecidos en distintas ciudades italianas de importancia por su relación con el Imperio, así como alusiones y representaciones de personajes del ámbito imperial -como es el caso de Conrado IV- o la mención específica de obras de arte que se estaban realizando en Italia en aquel momento. A través de estas plasmaciones artísticas y literarias Alfonso X parece haber querido dejar constancia de una Ida al Imperio que nunca se llegó a producir, de una aspiración imperial que no pudo hacerse realidad. El análisis de dichas plasmaciones puede aportar una valiosa información sobre las relaciones entre ambos países y sobre la producción artística llevada a cabo en cada uno de ellos.
\end{abstract}

Palabras clave: Alfonso X el Sabio, Cantigas, Siena, Foggia, Puglia.

\section{Journey to Italy through the Cantigas of Alfonso X the Wise}

\begin{abstract}
In the year 1256, the city of Pisa sent several embassies to Soria to propose to Alfonso X the candidacy to occupy the Imperial throne. These embassies appealed to the existence of blood ties that binded Alfonso the Wise to the Staufen dynasty. The offer made by these Italian ambassadors culminated in an imperial policy that had a great impact in the artistic production of Alfonso X. In the case of the Cantigas de Santa Maria, it is possible to find miracles that took place in different Italian cities that were very important due to their relation to the Holy Roman Empire, as well as allusions and representations of important figures of the Imperial field - such as Conrad IV — or of works of art that were created in Italy at that moment in time. Through these artistic and literary expressions, it is possible that Alfonso X wanted to create a record of a Journey to the Empire that never happened, of an imperial aspiration that could never take place. The analysis of these artistic expressions can contribute valuable information regarding the relations between both countries and the artistic production carried out in each of them.
\end{abstract}

Keywords: Alfonso X the Wise, Cantigas, Siena, Foggia, Puglia. 


\section{Introducción}

Son conocidas las relaciones establecidas entre el Reino de Castilla y el Imperio a partir del año 1256, cuando Alfonso X recibió la propuesta de la candidatura a la herencia de la corona Imperial a través de unas embajadas procedentes de la ciudad de Pisa ${ }^{1}$ encabezadas por Bandino de Lancia ${ }^{2}$. Desde este momento, las relaciones se fueron intensificando, debido a la búsqueda por parte del rey castellano de pactos con distintas ciudades que pudieran apoyar su candidatura. Este anhelo imperial ${ }^{3}$ llegó a su fin en el año 1275, cuando el Papa Gregorio X, en las entrevistas de Beaucaire, instó al Rey Sabio a renunciar a sus pretensiones imperiales, obligándole del mismo modo a abandonar el uso del título de Rey de Romanos en su documentación diplomática. Sin embargo, Alfonso X siguió utilizando dicho título hasta el año 1281, ganándose con ello la amonestación del Pontífice en distintas ocasiones ${ }^{4}$.

A lo largo del presente artículo, se intentará poner de manifiesto cómo estas relaciones políticas y diplomáticas tuvieron su reflejo en la producción de las Cantigas Historiadas de Alfonso X, siendo los Códices sometidos a estudio el Códice Rico de El Escorial (Ms. T.I.1) y el de Florencia (Ms. B.R.20)

Como punto de partida, será conveniente la realización de una recopilación esquemática de aquellas Cantigas ambientadas en ciudades italianas, que conforman un total de ocho relatos, que en gran parte se aglutinan en el Códice de Florencia. No han sido incluidos en esta relación aquellos relatos que, aún siendo protagonizados por personajes italianos, no se han ubicado en ninguna ciudad o región en concreto. De este modo, el esquema será el siguiente:

D Códice Rico de El Escorial Ms. T.I.1

- $\quad$ CANTIGA CXXXVI > Fols. 191v.- 192r. FOJA en PULLA (Foggia en Puglia)

> Códice de Florencia Ms. B.R. 20

- Fol. 16v. > ROMA. Santa Maria Maggiore.

1 El testimonio de dichas embajadas de encuentra en cuatro documentos conservados en el Archivio di Stato di Pisa. Todos ellos pertenecen al fondo "Diplomatico Atti Pubblici"; tres de ellos datan del 18 de marzo de 1256 y han sido catalogados bajo la nomenclatura 1256 marzo 18, ind. XIV, Soria di Spagna, mientras que el cuarto de ellos recoge los privilegios comerciales otorgados a la ciudad de Pisa, y ha sido recogido como 1256 aprile 16, ind. XIV, Soria di Spagna.

2 Personaje procedente de una prestigiosa familia de juristas del ámbito pisano entre los siglos XIII y XV. Para mayor información véase REGE CAMBRIN, Laura, La famiglia dei Casalei dalle origini alla metà del XIII secolo, Tesi di Laurea (relatore: Maria Luisa Ceccarelli Lemut), Università degli Studi di Pisa, Facoltà di Lettere e Filosofia, Pisa, 1988-1989.

3 MENÉNDEZ PIDAL, Ramón, "La expansión peninsular y mediterránea (c.1212-c.1350). La Corona de Castilla", en Historia de España, vol. XIII, Madrid, Espasa Calpe, 1990, p. 168.

4 Para una mayor información al respecto véase GONZÁLEZ JIMÉNEZ, Manuel, Alfonso X el Sabio, Ariel, Barcelona, 2004. El Capítulo X (pp. 272-293) trata la Ida al Imperio del Rey Sabio, dedicando un epígrafe al encuentro entre Alfonso X y Gregorio X. 
- Fols. 19v. -20r. > PULLA (Puglia).

- Fols. 21r. - 21v. > ROMA. San Juan de Letrán.

- Fols. 46r. - 47r. > LOMBARDÍA.

- Fols. 78r. - 79v. > ROMA. San Juan de Letrán.

- Fols. 92v. - 93r. > SENA (Siena). Púlpito de Nicola Pisano.

- Fols. 100v. - 101r. > CEZILLA (Sicilia). Erupción del Etna.

Se puede observar cómo las ciudades escogidas como escenario para los milagros, se encuentran en estrecha relación con la política imperial de Alfonso X. La aparición de Roma nos recuerda el papel crucial que jugaba el apoyo del Papa en la elección de los emperadores, mientras que la aparición de Puglia -Pulla según las Cantigas-, y en especial de Foggia ${ }^{5}$-Foja en el manuscrito alfonsí- se convierte en emulación de la sede central del imperio de Federico II, sita en dicha ciudad desde el año 1235 hasta la muerte del emperador en 1250, período conocido como el Regnum Italiae ${ }^{6}$.

Los milagros que se someterán a análisis a lo largo del presente artículo tienen en común los siguientes aspectos: se desarrollan en territorio italiano y se encuentran en estrecha relación con objetos artísticos reales. En concreto, serán estudiados los casos de Siena y Apulia (Puglia).

\section{El púlpito de Nicola Pisano en la Catedral de Siena (Ms. B. R. 20 Fols. 92v.-93r.)}

El estudio de la Cantiga ambientada en la ciudad de Siena, gira en torno a una obra maestra de la Historia del Arte, como es el púlpito de Nicola Pisano realizado para la catedral de dicha ciudad (fig. 1). Por ello, trataremos de poner en relación el texto alfonsí con las miniaturas y con las esculturas del púlpito, realizando pos-

5 La monarquía castellana ya había establecido relaciones con la ciudad de Foggia durante el reinado de Fernando III el Santo. Fue precisamente el infante don Fadrique, hijo de Fernando III y hermano menor de Alfonso X, el primero en tomar contacto con la sede imperial de Federico II en el año 1240, convirtiéndose en miembro de la corte del emperador conocido como Stupor Mundi durante el período de cinco años. Véase MOLINA LÓPEZ, Laura, "La entrada de un modelo arquitectónico federiciano en el Reino de Castilla: la Torre de don Fadrique", en GARCÍA GARCÍA, Francisco de Asís; GONZÁLEZ HERNANDO, Irene y PAULINO MONTERO, Elena (eds.), Nuevas Investigaciones en Historia del Arte. Anales de Historia del Arte, vol. ext., 2010, pp. 185-200.

6 Desde el momento de la coronación de Federico II en Roma el 22 de noviembre de 1220 hasta su muerte el 13 de diciembre de 1250 en Castel Fiorentino, pueden distinguirse dos etapas bien definidas por el traslado del centro de poder del Imperio. La primera abarcaría desde noviembre de 1220 hasta mayo de 1235 , y se caracterizaría por la actividad del emperador en territorio siciliano (Regnum Siciliae); mientras que en el período comprendido entre el 16 de mayo de 1235 y la muerte de Federico II en el año 1250, el escenario de los acontecimientos se trasladó al ámbito peninsular (Regnum Italiae). El centro neurálgico del imperio se puede situar durante el período del Regnum Italiae en la ciudad de Foggia, que acumula el mayor número de estancias (siendo también las más prolongadas) de la corte del emperador con motivo de celebración de festividades religiosas. Véase BRÜHL, Carlrichard, "L'itinerario dell'imperatore: 1220-1250”, en TOUBERT, Pierre y PARVICINI BAGLIANI, Agostino (a cura di), Federico II, vol. 3, Palermo, 1994, pp. 34-47. 


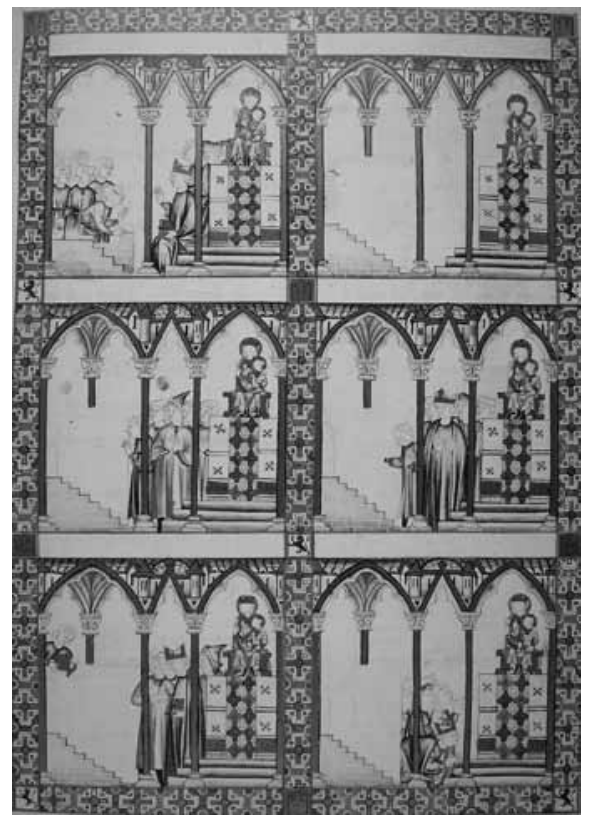

Fig. 1. Cantigas de Santa María, $2^{\mathrm{a}}$ mitad del siglo XIII, Florencia (Italia), Biblioteca Nazionale Centrale, Ms. B.R.20, fol. 93r. teriormente una confrontación con los documentos conservados sobre la realización del mismo.

El texto alfonsí ${ }^{7}$ relata cómo el obispo de la ciudad de Siena mandó construir un púlpito desde el cual poder predicar. Con tal fin hizo venir a escultores, que se encargarían de esculpir una imagen de la Virgen sosteniendo en los brazos a su Hijo, así como otras muchas escenas. Entre todas las imágenes representadas, había una que encarnaba la figura del demonio que, por ser la piedra de un blanco tan puro, "no parecía tan repelente como si hubiese sido negra". Por este motivo, la Virgen obró el milagro, ennegreciendo la figura del demonio. Cuando el obispo supo la noticia, no pudo dar crédito, por lo que no se demoró en ir a comprobarlo. Mandó a uno de sus hombres limpiar y raspar la figura, pero de nada sirvieron estos remedios para tornar blanca la represen-

7 El Códice de Florencia de las Cantigas de Alfonso X el Sabio : Ms. B.R. 20 de la Biblioteca Nazionale Centrale / Marco histórico y texto por SANTIAGO LUQUE, Agustín; las ilustraciones por CHICO PICAZA, María Victoria y DOMÍNGUEZ RODRÍGUEZ, Ana; la música por SANTIAGO LUQUE, Agustín; con un apéndice por REGUANT, Jordi, Madrid, Edilán, 1991, p. 93.

"Ésta es de cómo Santa María hizo que se volviese negra una figura del demonio que había sido esculpida en mármol blanco por hallarse junto a una imagen suya tallada en aquel mismo mármol.

$R$.- No está bien que al lado de la imagen de la madre del Rey glorioso haya una figura del infame diablo.

Que así como las tinieblas y la luz no se pueden juntar, por lógica son opuestas aquellas dos figuras: una, que nos da vida; otra, perdición. Y sobre esta cuestión os voy a contar un milagro muy placentero.// Hay en la Toscana una gran ciudad llamada Siena; según oí decir, su obispo mandó levantar en la catedral un púlpito de mármol, rico y hermoso, desde donde predicar.// Hizo venir a maestros escultores, a los que encargó que esculpiesen en mármol blanquísimo una imagen de la virgen Santa María que nos ampara, sosteniendo en los brazos a su Hijo precioso.// Mandó asimismo figurara en aquel mármol muchas otras escenas e historias, y ocurrió que, en una, aparecía el demonio, al que representaron en una figura muy deforme, como corresponde a su maldad.// Pero como el mármol era de un blanco muy limpio, la figura del demonio no parecía tan repelente como si hubiese sido negra, y la Virgen Santa, madre del Rey poderoso, no consintió en que quedara así.// Esto lo vio todo el mundo: llegó el momento en que la Virgen gloriosa obró su milagro, tan grande que en una hora volvió negra como la pez, feísima y repugnante, la figura del demonio.// Al día siguiente, los fieles que acudieron a oír misa y vieron el diablo ennegrecido, echáronse a reír; el obispo, cuando se lo contaron, pensó que querían engañarle y no se demoró en ir a comprobarlo.// Mandó a uno de sus hombres que lavase muy bien la figura y luego que la raspase, pero de nada sirvió, que la que nos mantiene la habia ennegrecido de tal modo que nada la podía aclarar. Y el obispo, muy lloroso,// fue a postrarse ante el altar y dijo: "Señora, me equivoqué al mandar tallar eso junto a tu imagen; te pido, pues, que me perdones, pues sé que, si lo haces no tendré contra mil/ a tu Hijo Jesucristo que es hombre y Dios y por ti perdona a muchos y los hace suyos. $Y$ yo haré poner este milagro entre los tuyos, porque bien creo que es muy maravilloso."// 
tación del demonio. Finalmente, el obispo se postró ante el altar para pedir perdón a la Virgen por haber mandado "tallar eso junto a tu imagen". Para cerrar la Cantiga el obispo afirma que hará poner ese milagro entre los de Santa María, lo que podría hacer pensar en la existencia de un mariologio promovido por el obispo ${ }^{8}$.

Sería oportuno realizar aquí un inciso histórico. El obispo de Siena durante el período en el cual se realizó el púlpito era Tommaso dei Balzetti Scotti (1254-1273). Entre sus hazañas, se encuentra la de haber encomendado a la Virgen la protección de la ciudad antes de la Batalla de Montaperti, en la cuál se enfrentaron Siena y Florencia y que tuvo lugar en septiembre de 1260. Esta misma fecha es muy significativa para el desarrollo de las relaciones diplomáticas del Reino de Castilla con la región de la Toscana, ya que antes de la mencionada batalla, se desplaza hasta Castilla una embajada procedente de Florencia ${ }^{9}$ encabezada por Brunetto Latini ${ }^{10}$, el maestro de Dante Alighieri ${ }^{11}$.

Volviendo al texto del Códice de Florencia, procederemos al análisis individual de cada uno de los numerosos datos que nos ofrece. En primer lugar, se especifica que el obispo "hizo venir escultores", lo que implica que fueron varias las manos que intervinieron en la realización del púlpito y que no eran naturales de la ciudad de Siena. Mediante la consulta de los documentos alusivos a la construcción del citado púlpito, descubrimos como el monje Melano se desplaza a Pisa para firmar el contrato con Nicola Pisano que se encontraba trabajando en el púlpito del Bap-

8 Ibid.

9 GONZÁLEZ JIMÉNEZ, Manuel (2004), op. cit., p. 136.

10 Es el propio embajador, en su obra Il Tesoretto, quien nos relata la embajada florentina que tuvo lugar en el año 1260. Del mismo modo nos informa sobre la candidatura de Alfonso X a la corona imperial, dejando también constancia del linaje que justifica su elección para tal fin: “[...] esso Comune saggio [Florencia]/mi fece suo mesaggio / all'alto re di Spagna, / ch'or è de la Magna / e la corona atende / se Dio no.llil contende: / che già sotto la luna / non si truova persona / che, per gentil legnaggio / né per altro barnaggio / tanto degno ne fosse / com'esto re Nanfosse. / E io presi campagna / e andai in Ispagna / e feci l'ambasciata / che mi fue ordinata [...]"' (LATINI, Brunetto, Il Tesoretto, Rizzoli, Milano, 1985, pp. 4 y ss.)

11 ALIGHIERI, Dante, Divina Commedia, Paraíso, Canto XIX, versos 124-126:

"Vedrassi la lussuria e 'l viver molle

di quel di Spagna e di quel di Boemme,

che mai valor non conobbe né volle"

En la obra de Dante Alighieri, podemos encontrar numerosa información sobre acontecimientos históricos que le eran contemporáneos. Se convierte así su obra, en una fuente documental para el conocimiento del conflicto que en Italia se estaba dando entre los bandos Güelfo y Ghibellino. En el fragmento citado anteriormente, queda plasmada la intervención de España -siendo quizá más apropiado decir de Castilla-, y la opinión que el poeta posee sobre el papel desempeñado por el rey. En su traducción y notación de la Divina Commedia, Conde de Cheste identificó a "quel di Spagna” con Alfonso X, candidato a la corona imperial y a "quel di Boemme" con Wenceslao. Por lo que respecta a esta última identificación, proponemos que se pudiera tratar de Ottokar II, elector partidario de Alfonso X que jugó un importante papel en la candidatura del Rey Sabio, siendo ambos nietos de Felipe de Suabia (Véase GONZÁLEZ JIMÉNEZ, Manuel (2004), op. cit., p. 117 ). 
tisterio de Pisa ${ }^{12}$. No sólo en dicho contrato, conservado por duplicado - una copia realizada por un notario de la ciudad de Pisa $^{13}$ y otra por un notario de Siena ${ }^{14}$,, se hace mención a los distintos escultores que deberán intervenir en el desarrollo escultórico del púlpito, sino también en documentos posteriores en los cuales Nicola reclama el pago de los salarios "Iohannis filii mei, et Lapi, Donato et Arnolfi, meorum discipulorum"15. En relación con esta información documental, podemos apreciar cómo el códice alfonsí, en su interés por el detallismo, pone énfasis en la existencia de varios maestros a través de la representación, en la caja A del folio 93r., de una cuadrilla de tres escultores encabezados por el que sería el maestro.

Por otro lado, se cita en el texto cómo dichos escultores deberán utilizar un "mármol blanquísimo" para realizar las esculturas, hecho que podemos contrastar una vez más con los documentos, en los cuales se especifica que el material utilizado deberá ser mármol de Carrara ${ }^{16}$.

Se pone de manifiesto que en el púlpito, además de la escultura de la Virgen con el Niño, se representan "muchas otras escenas". A este respecto debemos destacar cómo este púlpito fuera el mayor realizado hasta el momento, en un afán por poseer para la catedral de Siena un púlpito similar al de Pisa pero más amplio y rico ${ }^{17}$.

Por último quisiera hacer mención al hincapié realizado a lo largo de la narración sobre la cercanía entre las figuras de la Virgen y el Demonio, en especial en el estribillo "No está bien que al lado de la imagen de la Madre del Rey glorioso haya una figura del infame diablo". Es sabido que el púlpito no se encuentra en su ubicación original, y que sufrió alteraciones en la colocación de las figuras de los ángulos. Un ejemplo significativo es la aparición de uno de los grupos de ángeles tocando las trompetas dando paso a la escena de la matanza de los inocentes, cuando su posición correcta se encontraría junto al antepecho en el cual se representa el Juicio Final ${ }^{18}$. La única fuente gráfica hallada en relación a la ubicación del púlpito en la catedral antes de la reorganización del coro, llevada a cabo en el siglo XVI ${ }^{19}$, es una pintura sobre tabla conservada en el Archivio di Stato di Siena (fig. 2), en la cual se muestra una vista del interior de la catedral hacia el año 1480. Gracias a esta representación del interior de la catedral, podemos conocer cual fue la ubicación

12 Dichos acuerdos se llevaron a cabo en el Baptisterio de Pisa. Los documentos lo plasman de la siguiente manera: "Actum Pisis in ecclesia Sancti Iohannis Battiste”. Consultados en CARLI, Enzo, Il Pulpito di Siena, Bergamo, 1943, pp. 41-44; NICCO FASOLA, Giusta, Nicola Pisano. Orientamenti sulla formazione del gusto italiano, Roma, 1941, pp. 209-214.

13 NICCO FASOLA, Giusta (1941), op. cit., pp. 209 y ss.

14 NICCO FASOLA, Giusta (1941), op. cit., pp. 211 y ss.

15 NICCO FASOLA, Giusta (1941), op. cit., pp. 215-216.

16 Véanse las notas 13 y 14.

17 CARLI, Enzo, Il Pulpito di Siena, Bergamo, 1943, p. 11.

18 CARLI, Enzo (1943), op. cit., p. 49.

19 CARLI, Enzo (1943), op. cit., p. 49. 


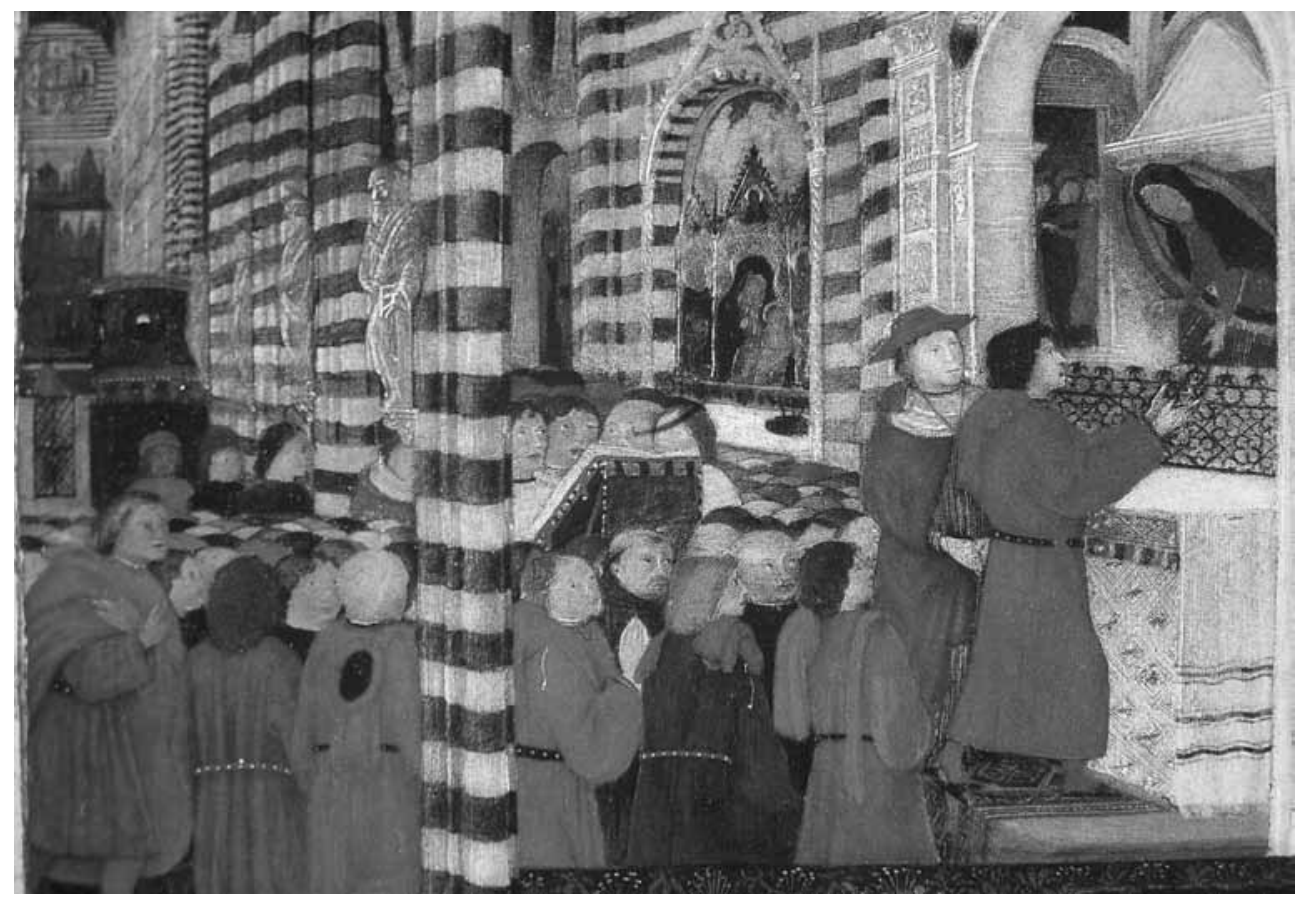

Fig. 2. Pietro di Francesco Orioli, L'unione delle classi e l'offerta delle chiavi della città alla Madonna delle Grazie (detalle), 1483, temple sobre tabla, 59,1 x $40 \mathrm{~cm}$., Siena (Italia), Archivio di Stato. [Tomado de BELLOSI, Luciano, Francesco di Giorgio e il Rinascimento a Siena (1450-1500), Milano, 1993, p. 367]

original del púlpito, a pesar de que, encontrándose cubierto por unos paños rituales, no nos muestra ningún detalle acerca de la disposición de las escenas.

Ante esta recopilación de datos ofrecidos por el texto del Códice, podemos afirmar que los conocimientos que se tenían de esta obra eran de una elevada concreción, hecho que puede ir asociado a la ya mencionada existencia de un libro de milagros de Santa María promovido por el obispo de Siena. Sin embargo, en cuanto a las imágenes se refiere, se puede apreciar cómo el púlpito se encuentra apenas esbozado, encontrándose, quizá, reservada su realización para un maestro principal que pudiera representar una estructura tan ajena a la tradición ibérica.

\section{Puglia (Ms: T-I-1 Fols. 191v.- 192r. y Ms. B. R. 20 Fols. 19v. - 20r.)}

Al abordar aquellas cantigas ambientadas en la región de Puglia, nos enfrentamos a dos relatos cargados de similitudes, sin embargo, el análisis exhaustivo de cada una de ellas nos hará apreciar algunos matices que las hacen diferentes (fig. 3). En ambos poemas se narra la historia de una mujer que se encuentra jugando a los dados junto a una iglesia y presa de la ira, por ir perdiendo en el juego, intenta agredir a la imagen de la Virgen con el Niño. Parece ser que la fuente de la cual beben 

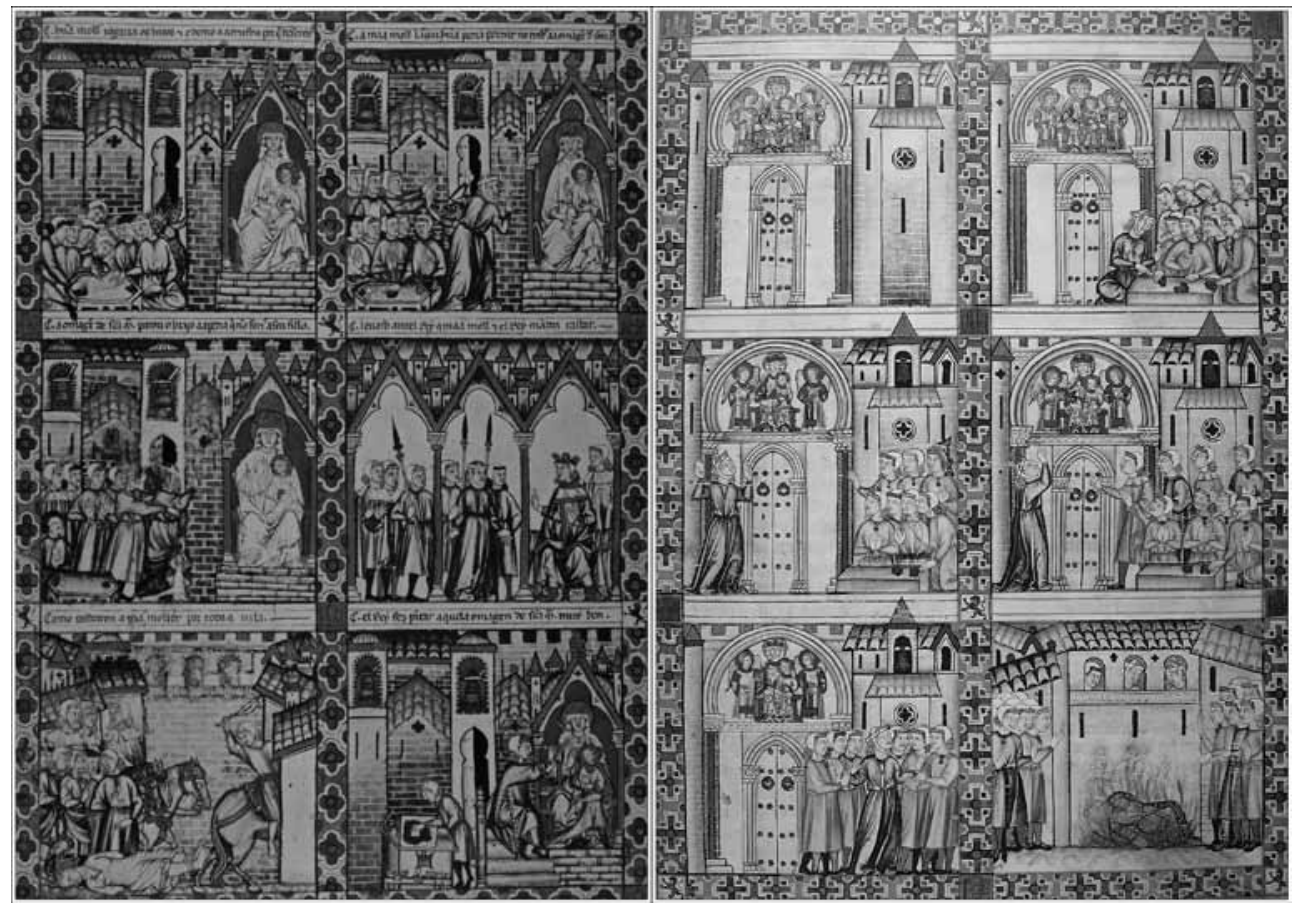

Fig. 3. Cantigas de Santa María, $2^{\text {a }}$ mitad del siglo XIII, San Lorenzo de El Escorial (España), Real Biblioteca del Monasterio de El Escorial, Ms. T.I.1, fol. 192r. / Cantigas de Santa Maria, $2^{\mathrm{a}}$ mitad del siglo XIII, Florencia (Italia), Biblioteca Nazionale Centrale, Ms. B.R.20, fol. 20r.

estos relatos es de procedencia alemana ${ }^{20}$, apuntándose en repetidas ocasiones a la relación con los Diálogos de Milagros de Cesario de Heisterbach. De entre estos relatos, podríamos poner en relación con las Cantigas el Capítulo 44 de la Séptima Distinción ${ }^{21}$, en el cual nos habla de dos jugadores, uno de los cuales no tenía suerte y dando rienda suelta a su furor, comenzó a blasfemar contra Dios, pero su compañero le acusó de no saber hacerlo, y cuando empezó a blasfemar contra la Virgen, por intervención de Cristo, cayó fulminado sobre la mesa en la cual estaba jugando.

En el caso de la Cantiga CXXXVI del Códice Rico de El Escorial (Ms. T.I.1), el relato se ubica en una ciudad concreta de la región de Puglia: Foggia ${ }^{22}$. El ataque de la mujer va dirigido a una imagen de la Virgen con el Niño que, según el texto,

${ }^{20}$ El "Códice Rico" de las Cantigas de Alfonso X el Sabio: Ms. T.I.1 de la Biblioteca de El Escorial / el códice por LÓPEZ SERRANO, Matilde; el texto por FILGUEIRA VALVERDE, José con apéndice de LORENZO VÁZQUEZ, Ramón; las miniaturas por GUERRERO LOVILLO, José / la música por LLORÉNS CISTERÓ, José María, Madrid, Edilán, 1979, p. 211.

21 CESARIO DE HEISTERBACH, Diálogo de Milagros, Introducción, versión y notas de PRIETO HERNÁNDEZ, Zacarías, Zamora, Ediciones Monte Casino, 1998, vol. II, p. 605.

22 Véase nota 5. 
goza de gran devoción entre la población y entre la realeza de la región, hecho demostrable por la introducción de la figura del rey Conrado IV ${ }^{23}$ como responsable de aplicar el castigo a la agresora, así como su representación en las miniaturas que ilustran el relato.

A pesar de tratarse, siguiendo el relato, de una obra realizada en mármol ${ }^{24}$, podemos ver cómo en las miniaturas se representa como si de una pintura sobre tabla se tratara, dotada de un aire de icono bizantino (fig. 4).

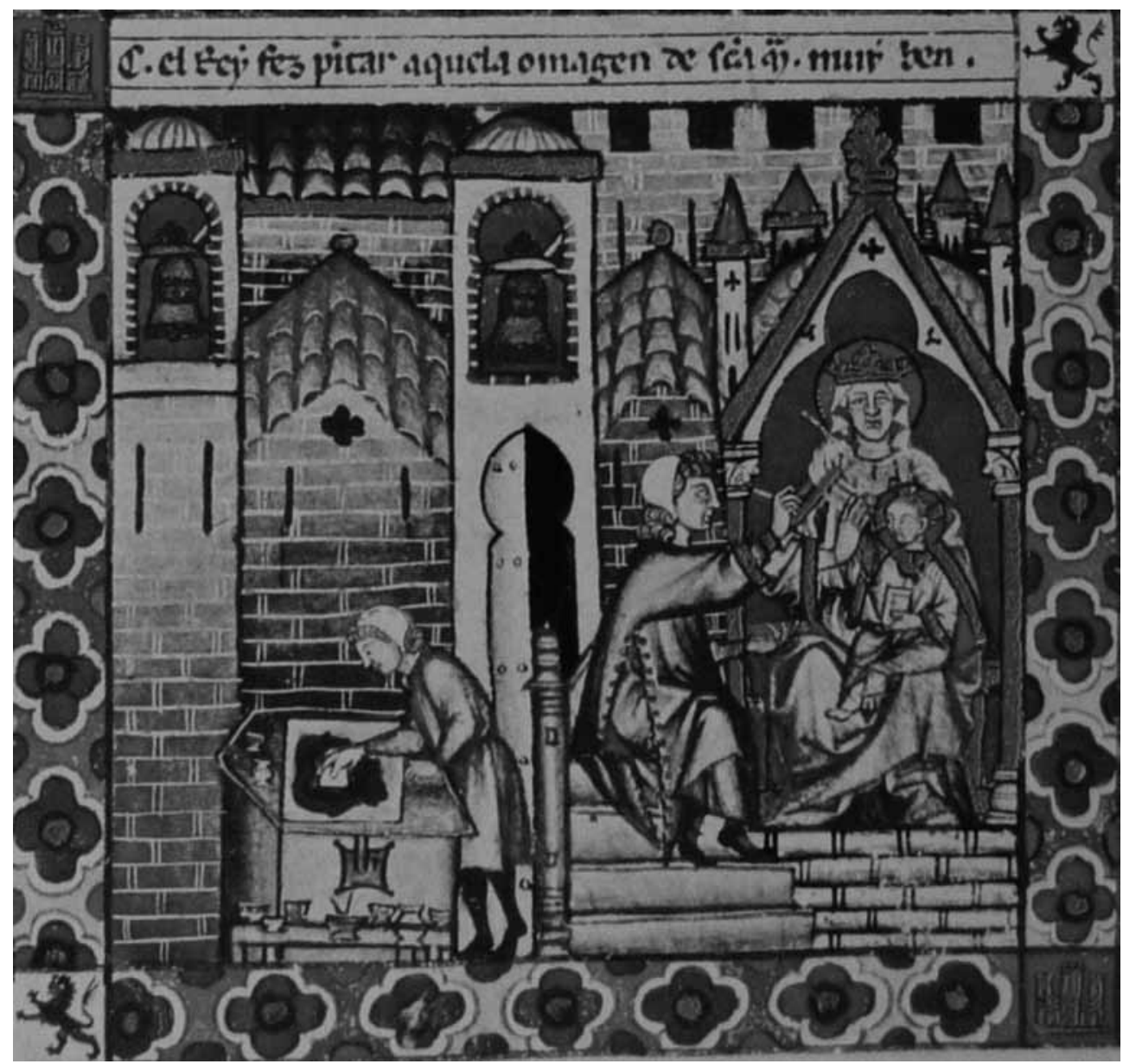

Fig. 4. Cantigas de Santa María, $2^{\mathrm{a}}$ mitad del siglo XIII, San Lorenzo de El Escorial (España), Real Biblioteca del Monasterio de El Escorial, Ms. T.I.1, fol. 192r. Detalle caja F.

23 El texto de la cantiga CXXXVI del Ms. T.I.1, fol. 191v., relata lo siguiente: “En essa vila, segund'eu aprix en verdade, fillo do Emperador ý era Rey Corrade".

24 “Esto na villa de Foja foi ant' una' egrejia / ú estavu h a omage da que sempre seja /b eita, feita de mármor, de mui gran sobeja / beldade, en que as gentes avian fiança.” 
El origen de la ciudad de Foggia, según la tradición religiosa, se encuentra ligado al hallazgo de un antiguo icono en el año 1062. Se trata de la Madonna Iconavetere o Madonna dei Sette Veli, una témpera sobre tabla en la cual se representa a la Virgen con el Niño, datada entre los siglos XI y XII, objeto de gran veneración en la ciudad ${ }^{25}$. En la actualidad, este icono se encuentra en la Catedral de Foggia, cubierto por siete velos en una teca de plata realizada por el artista napolitano Giovan Domenico Vinaccia en $1691^{26}$. Fue en la década de 1980 cuando, gracias a la realización de unas labores de restauración de la tabla, se pudo reconocer la representación de una imagen sedente de la Virgen, ricamente vestida, con el Niño en su regazo ${ }^{27}$. De esta misma restauración se extraen datos como el uso de lapislázuli y de oro en la elaboración del icono ${ }^{28}$. Observando las ilustraciones del folio 192r. del Códice Rico (Ms. T.I.1), nos encontramos con una imagen de la Virgen sedente, con el Niño en su regazo, sobre un fondo azul y con numerosos detalles trabajados en oro -como la corona o el trono- que bien podría identificarse con la imagen de la Iconavetere o Madonna dei Sette Veli ${ }^{29}$.

$\mathrm{Al}$ aproximarnos al estudio del relato plasmado en los folios 19v. y 20r. del Códice de Florencia (Ms. B.R.20), la ubicación de los acontecimientos se refiere a la región de Puglia, aunque sin especificar ninguna ciudad en concreto. Sin embargo, las miniaturas del Códice Florentino nos ofrecen la representación de una portada muy detallada (fig. 5a), que cobra un relevante protagonismo en cada una de las escenas. Es interesante ver cómo esta misma tipología de portada, con el mismo tema iconográfico, se encuentra en la Catedral de Santa Maria Assunta in Cielo de Foggia, concretamente en el Portale di San Martino ${ }^{30}$ (fig. 5b), en cuya realización intervino Bartolomeo di Foggia, arquitecto y escultor que trabajó también en la construcción del Palacio de Federico II en Foggia ${ }^{31}$.

25 ROMANINI, Angiola Maria (dir.), Enciclopedia dell'arte medievale, Istituto della Enciclopedia Italiana, vol. VI, Milán, 1995, pp. 268-271.

${ }^{26}$ LOPRIORE, Lucia, Il culto Della Madonna Iconavetere a Foggia, 2005, publicación on line http:// www.mondimedievali.net/microstorie/iconavetere.htm

27 LOPRIORE, Lucia (2005), op. cit.

28 LOPRIORE, Lucia (2005), op. cit.

${ }^{29}$ La posible identificación de esta imagen con la Madonna dei Sette Veli será analizada en profundidad a lo largo de la Tesis Doctoral de la autora. Por el momento, mantenemos que se trata de una pintura sobre tabla, y no de un grupo escultórico, debido a su organización iconográfica y a la escena representada en la última caja, en la que aparece un pintor con los pinceles y pigmentos dispuesto a restaurar la imagen tras la agresión sufrida por parte de la mujer.

30 CALÒ MARIANI, Maria Stella, "La Scultura in Puglia durante l'età sveva e proto-angioina", en VV.AA., La Puglia: fra Bisanzio e l'Occidente, Milano, 1980, pp. 255 y ss.

31 En la actualidad solamente se conserva el arco de ingreso del Palatium de Federico II en la ciudad de Foggia. En la lastra epigráfica ubicada en el interior del arco, quedan inmortalizados los nombres del arquitecto y el comitente de la obra:

"SIC.CESAR.FIERI.IUSSIT.OPUS.ISTUN.PTO.BARTOLOMEUS.SIC CONSTRUXIT.ILLUD".

(Borde superior de la lastra)

"+A(NNO).ABI(N)CARNATIO(N)E.M.C.C.XX.III.M.IUNII.XI.IND.R.D(OMINO).N(OSTRO)

FREDERICO.IMP(ER)ATORE.R.SE(M)P(ER).AUG(USTO).A.III.ET.REGE.SICILE.A.XXVI

HOC.OPUS.FELICIT(ER).INCEPTUM.EST.P(RAE)PHATO.D(OMI)NO.P(RAE)CIPI(N)TE”

(Interior de la lastra) 


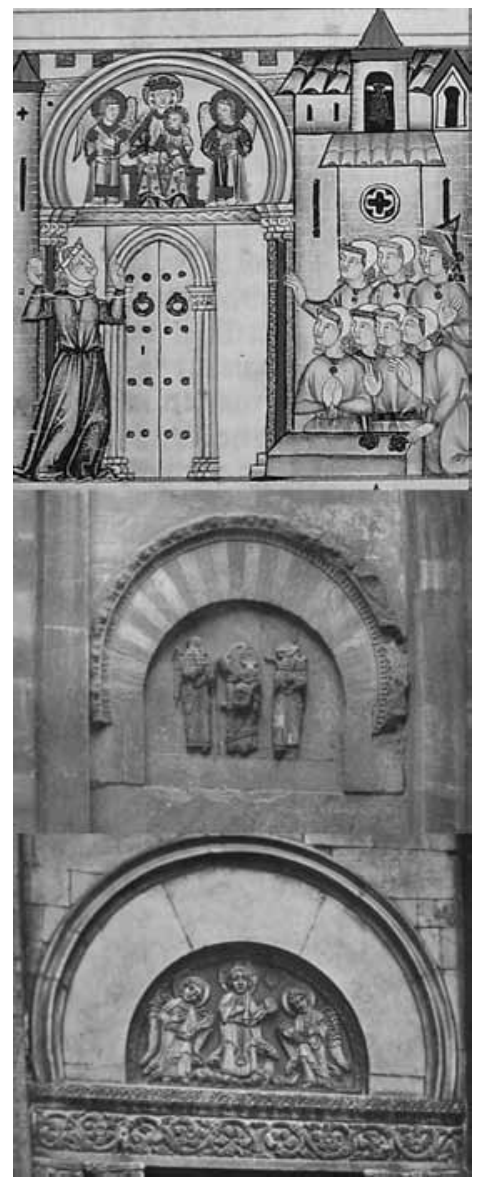

El templo de Santa Maria de Foggia, actual catedral, gozó de gran importancia durante el siglo XIII, y buena prueba de ello es que fuera elegido por importantes monarcas para depositar sus restos tras su muerte. Por un lado, Federico II depositó su corazón y sus vísceras en una urna que se ubicó en la portada principal del templo ${ }^{32}$, mientras que Carlos de Anjou eligió esta catedral para cobijar parte de sus vísceras ${ }^{33}$. Todo ello nos lleva a cuestionarnos si con una plasmación tan meticulosa de la portada de un edificio se pretendería la representación simbólica de la ciudad.

Las imágenes que ilustran el texto, ambientando el relato ante una portada ultrasemicircular de una iglesia de la región de Pulla, muestran también numerosas analogías, en lo que a estructura se refiere, con otras portadas de edificios religiosos de Puglia, como es el caso de la Cattedrale di Troia (fig. 5c), ciudad

Fig. 5. a) Cantigas de Santa María, $2^{\mathrm{a}}$ mitad del siglo XIII, Florencia (Italia), Biblioteca Nazionale Centrale, Ms. B.R.20, fol. 20r. Detalle caja C; b) Catedral de Foggia, Puglia (Italia), $1^{\mathrm{a}}$ mitad del siglo XIII [Tomado de CALÒ MARIANI, Maria Stella: "La Scultura in Puglia durante l'età sveva e proto-angioina", en VV. AA., La Puglia: fra Bisanzio e l'Occidente, Milano, 1980, p. 256]; c) Catedral de Troia, Puglia (Italia), ca. 1120 [Tomado de BELLI D’ELIA, Pina: "Il Románico", en VV. AA., La Puglia: fra Bisanzio e l'Occidente, Milano, 1980, p. 181]

"HOC.FIERI.IUSSIT.FREDERICUS.CESAR.UT.URBS.SIT.FOGIA.REGALIS.SEDES.INCLITA. IMPERALIS".

(Borde inferior de la lastra)

Véase RESTA, Fulvio, "Il portale del Palazzo di Foggia", en CALÒ MARIANI, Maria Stella y CASSANO, Raffaella (a cura di), Federico II. Immagine e potere, Bari, 1995, pp. 234-237.

32 VILLLANI, Ferdinando, Foggia al tempo degli Hohenstaufen e degli angioini. Con Prefazione ed Appendice di Carlo Villani, Trani, 1894, pp. 49-51: "Il cadavere di Federico II fu intanto trasportato in Foggia e venne imbalsamato, giusta l'usanza dei tempi;nè è a dire con quanta pompa furono celebrati i suoi funerali. Il cuore e i visceri del re furono custoditi in un'urna, e questa fu collocata sopra un arco sorretto da quattro colonne di verde antico in cima della porta maggiore della chiesa; il quale monumento andò disperso pel tremuoto del 1731".

33 VILLANI, Ferdinando (1894), op. cit., pp. 77-78: “...ivi [Foggia] morì [Carlo d'Angiò] nel 7 di gennaio 1284. Aveva già ordinato egli stesso che il suo cuore, chiuso in un'urna, venisse deposto nella chiesa palatina dei suoi maggiori in Francia, il corpo in Napoli, e le altre viscere nella chiesa di Foggia, a cui donò molte reliquie cesellate in argento con le parole: ex dono Reg. Caruli I Adegavensis." 
que había sido uno de los principales baluartes del papado en la Terra di Puglia ${ }^{34}$. Con todo ello, podemos atisbar la latente necesidad de profundizar más en el estudio de estos relatos y de su ubicación y valoración dentro del contexto histórico en el que se dieron.

\section{Conclusiones}

Los datos expuestos a lo largo de este artículo, nos plantean numerosos interrogantes, como el de cómo fue posible alcanzar un conocimiento tan detallado de estas producciones artísticas, el de quién realizó estas representaciones o el de si sería posible pensar en la intervención directa de algún miniaturista procedente de Italia o que hubiera tenido la posibilidad de visitar las ciudades representadas.

Con esta relación de datos e imágenes mi propósito ha sido el de elaborar, a partir de noticias aparentemente inconexas, un entramado que nos ofrezca una mejor comprensión de las relaciones del Reino de Castilla con el Imperio, tanto en el ámbito histórico como en el artístico a través de la información que nos ofrecen tanto los textos como las imágenes de las Cantigas de Santa María.

34 BELLI D’ELIA, Pina, “Il Romanico”, en VV. AA. (1980), op. cit., pp. 177 y ss. 